\title{
Engaging students affectively to stimulate social presence in online learning
}

\author{
Xiaowen Gao \\ University of Greenwich, UK
}

\begin{abstract}
There is challenge in designing online teaching that motivates students and encourages them to engage fully with learning activities. This conference reflection considers how affective engagement may be supported and why addressing it should be a priority when designing and delivering effective online teaching.
\end{abstract}

Keywords: affective engagement, online delivery, pedagogical design

The rapid move from classroom-based to online teaching in 2020 has presented new challenges for educators seeking to engage students effectively in a virtual environment. Compared with classroom-based teaching, where educators can use a wide range of delivery strategies - verbal and non-verbal communication, group activities and classroom layouts to facilitate students' active learning (Christophel, 1990) - it can be more difficult to do this when delivering online, when students are more likely to take a passive role or even fail to engage at all. Possible explanations are: lack of confidence about using the technology and, in some cases, inadequate access to it; a feeling of being disconnected from others; lower levels of motivation and interest, which can be associated with a sense of isolation (Smith and Smith, 2014; Ward and Newlands,1998; Bullen, 1998).

To address these challenges, various ideas were presented at the University of Greenwich Business Faculty's Teaching and Learning Festival in July 2020. It was the first time that the festival was held virtually, but, as in previous years, there was energetic discussion between colleagues eager to participate and share their experiences. They voiced concerns that students may not have access to the high speed of internet connection needed for video or audio interactions. In addition to such technological limitations, it was recognised that creating a sense of belonging is even more challenging in an online environment. For example, it is relatively easy to give personal attention to each student in a classroom, but much more difficult to do so in an online class.

Among the diverse contributions made at the festival, I was particularly interested in presentations focusing on methods for stimulating active learning online. These included using a wiki page for collaborative asynchronous learning and applying a jigsaw classroom method to online tutorials. Inspired by these presentations, I reflected on the methods that my colleagues and I have deployed in our online modules. In this brief piece, I consider why and how we could do more to support students' affective engagement, so as to motivate their participation in online learning in addition to engaging them with activities aimed at supporting cognitive engagement and progress in subject knowledge.

Undoubtedly, text-based asynchronous online collaborative learning activities, such as contributing to a wiki page or discussion forum, have their strengths. They create 
opportunities for students to articulate and share their understanding of academic content and can be seen as student-centred, in that students can participate at their convenience. However, because there is no immediate response or feedback, it can be argued that they do little to address the problem of learner isolation (Moore et al., 2005). Synchronous online learning, on the other hand, allows interactions in real time or live sessions (Moore et al., 2011), but, on the recurrent evidence of my own teaching and that of others who presented at the festival, students did not turn their webcams on to show their faces or were not keen to participate in live tutorials. These teaching sessions consequently proved less than successful in cultivating a sense of belonging and may not have served to motivate students or stimulate their interest in learning and lead them to value it.

At the festival, I presented to the audience my design and execution of an online delivery to a group of third-year students in China. According to the Community of Inquiry (Col) model proposed by Garrison and Arbaugh (2007), to create an online learning experience in which deep and meaningful learning is supported, three interdependent elements must be developed: social, cognitive and teaching presence. My focus now, in reflecting on the festival, is on the way that I approached the development of social presence. In the Col model, this refers to the ability, in an online environment, to perceive others as 'real' and to project oneself as real, too. This involves affective expressions, open communications and group cohesion (Garrison and Arbaugh, 2007). Social presence is supported by increased interactivity among participants (Melrose and Bergeron, 2006).

For my module, I designed opportunities to support affective engagement by using activities that would help develop a sense of belonging to the group. I implemented this approach in several ways. In the first few sessions of the module, word-cloud questions on Mentimeter enabled tutor and students to interact with each other, providing them with opportunities to share information about themselves and learn about the other members of the group. The questions sought responses about participants' hobbies, the role models they valued and the reasons for their interest - or lack of it - in the subject learning. Shared interests and themes became apparent and triggered further interactions. During each live session, I organised small group discussions and ensured that I asked questions of students individually and directly, by using their names. This helped to build familiarity between members of the group. When I allocated students to small groups to take part in learning activities, I created the groups randomly each time, in order to maximise the opportunities for students to connect with others in the group and to prevent the formation of cliques. A group presentation video recording, used in the assessment of the module, also provided a collaborative learning experience. I asked students to discuss and decide on a name for their group, so as to enhance group rapport.

At the festival, so as to make improvements to my future practice, I sought feedback from participants; they were both positive and complimentary about my presentation. Some regarded my approach as useful and said they would consider applying it to their own online delivery design. Others shared their own suggestions for helping students to establish social connections. In reflecting on these discussions, I would argue that a key priority in online teaching is to engage students affectively and develop social presence. There may be many ways to approach this, but, however it is done, it is a necessary part of online learning. 
My reflections on this festival conference have led me to conclude that, although social presence cannot on its own produce learning outcomes for students, achieving effective online learning without it is extremely difficult.

\section{Reference list}

Bullen, M. (1998) 'Participation and critical thinking in online university distance education.' Journal of Distance Education,13(2),1-32. Available at:

http://www.ijede.ca/index.php/jde/article/download/140/394?inline=1 (Accessed: 28 May 2021).

Christophel, D. (1990) 'The relationships among teacher immediacy behaviors, student motivation, and learning.' Communication Education, 39, 323-340. Available at: https://www.tandfonline.com/doi/abs/10.1080/03634529009378813 (Accessed: 27 May 2021).

Garrison, D.R. and Arbaugh, J.B. (2007) 'Researching the community of inquiry framework: Review, issues, and future directions.' The Internet and Higher Education, 10(3), 157-172. Available at: https://www.sciencedirect.com/science/article/pii/S1096751607000358 11

Moore, J.L. and Marra, R.M. (2005) 'A Comparative Analysis of Online Discussion Participation Protocols.' Journal of Research on Technology in Education, 38(2), 191-212. Available at: https://www.tandfonline.com/doi/abs/10.1080/15391523.2005.10782456 (Accessed: 28 May 2021).

Moore, J.L., Dickson-Deane, C. and Galyen, K. (2011) 'e-Learning, online learning, and distance learning environments: Are they the same?' The Internet and Higher Education, 14(2), 129-135. Available at:

https://www.sciencedirect.com/science/article/abs/pii/S1096751610000886 (Accessed: 28 May 2021).

Smith, D. and Smith, K. (2014) 'The Case for 'Passive' Learning - The 'Silent' Community of Online Learners.' European Journal of Open, Distance and E-Learning, 17(2), 85-98.

Available at: https://content.sciendo.com/view/journals/eurodl/17/2/articlep86.xml?product=sciendo (Accessed: 10 August 2020).

Melrose, S. and Bergeron, K. (2006) 'Online Graduate Study Health Care Learners' Perceptions of Instructional Immediacy.' The International Review of Research in Open and Distributed Learning, 7(1). Available at: http://www.irrodl.org/index.php/irrodl/article/view/255 (Accessed: 30 May 2021).

Ward, M. and Newlands, D. (1998) 'Use of the Web in undergraduate teaching.' Computers and Education, 31(2), 171-184. Available at: https://www.sciencedirect.com/science/article/abs/pii/S0360131598000244?via\%3Dihub (Accessed: 24 May 2021). 